\title{
THE SIMPLE ADDITIVE WEIGHTING METHOD APPLICATION IN FOOD SECURITY ASSESSING
}

\author{
Alina R. Battalova ${ }^{1}$ \\ Nadezda A. Opokina ${ }^{2}$
}

\begin{abstract}
: raditionally the problem of food security was the center of attention in domestic and foreign economic science and practice that was connected with challenges of world development and increase of global contradictions. Food security is an important element of economic and national security of the state in general. It is one of the necessary conditions of sustainable development in the region. Regional features influence safety of the region and as a consequence the safety of the country in general. The methodical approach based on an expert pair comparison method and the SAW method was developed for assessing the food security condition in the regions. The Volga Federal District (VFD) and the Republic of Tatarstan (RT) were chosen as a research object. The received method was applied to assessing the level of ensuring food security in regions
\end{abstract} of Volga Federal District and the largest regions of the Republic of Tatarstan. This technique allows to fully estimate stability of the food sphere in the economic security of the region in general and the territorial subjects of the Russian Federation which are its part, as well as to reveal strong points and weaknesses of the region and its subjects for the purpose of increasing the management efficiency and proving measures of the operating influence, directed to its increase.

Keywords: food security, assessment, SAW method, expert method, criteria of ensuring food security.

\section{Introduction}

Assessing the food security condition defines need of developing the system of objective criteria and methods

\footnotetext{
${ }^{1}$ Kazan Federal University, Institute of Management, Economic and Finance, e-mail: alina.sr@mail.ru

${ }^{2}$ Kazan Federal University, Institute of Mathematics and Mechanics named after N.I. Lobachevsky, candidate of Phisical and Mathematical sciences, e-mail: opnadin@mail.ru 89172570455
} 
of its quantitative measurement at the international and intra economic levels, as well as at the level of the region, area, and social population group. Food security contains three aspects (quantitative, qualitative and social-andeconomic); it is means that assessing the problem of food security has to be carried out within these aspects. The first is focused on ensuring sufficient volume of food; the second characterizes providing people not just with food, but food safe and qualitative. The third aspect provides increase in the income of the population or its separate groups to the level providing real (economic) access to food [1].

Today in order to estimate food security various statistics and dynamics are usually calculated $[2,3]$. We offer an algorithm of assessing the regional food security. The developed model is based on a technique of assessing the food security at the regional level of economy. This method is universal and allows carrying out the food security level assessing by regions of the country in comparison. This model studies food security of regions, using criteria for evaluation of food security in the region.

\section{Methods}

During the research we applied an expert pair comparison method to define the priority importance of ensuring food security criteria $[4,5]$. This method allows analyzing relation between the considered elements. Priorities of criteria concerning their importance to each other are defined as follows. They are compared with each other on their superiority $[6,7]$. The scale of the relative importance for comparison of criteria is presented in table 1.

Table 1: Scale of the criteria relative importance

\begin{tabular}{|c|c|c|}
\hline Importance & Definition & Explanation \\
\hline 0 & Are incomparable & The expert is at a loss in comparison \\
\hline 1 & Equal importance & Equal contribution \\
\hline 3 & $\begin{array}{c}\text { Moderate superiority of one over } \\
\text { another }\end{array}$ & $\begin{array}{c}\text { One criterion surpasses over another a } \\
\text { little }\end{array}$ \\
\hline
\end{tabular}


ISSN | 2179-7137 | http://periodicos.ufpb.br/ojs2/index.php/ged/index

\begin{tabular}{|c|c|c|}
5 & Essential or strong superiority & $\begin{array}{c}\text { One criterion strongly surpasses over } \\
\text { another }\end{array}$ \\
\hline 7 & Significant superiority & $\begin{array}{c}\text { One criterion is largely more significant } \\
\text { than the another }\end{array}$ \\
\hline 9 & Very strong superiority & $\begin{array}{c}\text { One criterion very strongly surpasses } \\
\text { another }\end{array}$ \\
\hline $2,4,6,8$ & $\begin{array}{c}\text { Intermediate values between two } \\
\text { similar judgments }\end{array}$ & Compromise solutions \\
\hline
\end{tabular}

We make a matrix on the following algorithm. Let comparison be made for criterion, being in the left column, concerning criterion, being in the top line. When comparing criteria which have the equal importance therefore the elements standing on the main diagonal of this matrix are equal to 1. The elements received at the return comparison of the same criteria are given the corresponding inverse values: 1 , $1 / 3 \ldots, 1 / 9$. The received matrix is a matrix of paired comparisons.

Let's say $n$ of criteria is considered. Experts establish criteria values by pair comparison method. Paired comparison - is the most expressive way for detection of elementary preferences. The pair comparison method is convenient; experts can compare indicators among themselves which is important having a large number of indicators. Investigating information obtained from experts by statistical methods it is necessary to estimate coherence of their opinions.

We will designate an indicator of the priority criteria values through $d_{i j}$ $(i, j=\overline{1, n})$. This indicator designates the relation of the importance of $i$ and $j$ of criteria. Let results of paired comparison be reduced in a matrix of $D$

$$
D=\left(\begin{array}{cccc}
d_{11} & d_{12} & \ldots & d_{1 n} \\
d_{21} & d_{22} & \ldots & d_{2 n} \\
\ldots & \ldots & \ldots & \ldots \\
d_{n 1} & d_{n 2} & \ldots & d_{n n}
\end{array}\right) .
$$

Elements of a matrix D are set as follows:

$$
d_{i j}=1, \quad d_{j i}=\frac{1}{d_{i j}} \quad(i, j=\overline{1, n}) .
$$

Then the matrix of $\mathrm{D}$ has an appearance: 


$$
D=\left(\begin{array}{cccc}
1 & d_{12} & \ldots & d_{1 n} \\
\frac{1}{d_{12}} & 1 & \ldots & d_{2 n} \\
\dddot{1} & \ldots & \ldots & \ldots \\
\frac{1}{d_{1 n}} & \frac{1}{d_{2 n}} & \ldots & 1
\end{array}\right) .
$$

Further we calculate a vector of priorities on this matrix. Its coordinates are calculated by a formula

$$
\sqrt[n]{\prod_{j=1}^{n} d_{i j}}
$$

where $i, j=\overline{1, n}$. Further we normalize the received vector, i.e.

$$
g_{i}=\frac{\sqrt[n]{\prod_{j=1}^{n} d_{i j}}}{\sum_{i=1}^{n} \sqrt[n]{\prod_{j=1}^{n} d_{i j}}}, \quad(i=\overline{1, n}) .
$$

$\mathrm{g}_{\mathrm{i}}$ number $(i=\overline{1, n})$, calculated by a formula (1), are numerical value of the importance of $i$ criterion $(i=\overline{1, n})$.

For application of a pair comparison method, we use the expert method and a way of coherence check for expert opinions offered by $\mathrm{L}$. Evlanov [8]. This technique is as follows.

Let there is $k$ of experts. Under each questionnaire indicators of the importance of subjects to comparison are received. Let $\mathrm{q}_{\mathrm{ij}}$ - ranks $\mathrm{i}$ subject to comparison of $j$ by the expert $(i=\overline{1, n}, j=\overline{1, k})$. Results of expert poll can be entered in the following table.

Table 2:Results of expert poll

\begin{tabular}{|l|l|l|l|l|l|l|c|}
\hline \multirow{2}{*}{$\begin{array}{l}\text { Subjects to } \\
\text { comparison }\end{array}$} & \multicolumn{5}{|c|}{ Experts } & $\begin{array}{c}\text { Sum of } \\
\text { ranks }\end{array}$ & $\begin{array}{c}\text { Average } \\
\text { rank }\end{array}$ \\
\cline { 2 - 8 } $\mathrm{X}_{1}$ & $\mathrm{q}_{11}$ & $\mathrm{q}_{12}$ & $\mathrm{q}_{13}$ & $\ldots$ & $\mathrm{q}_{1 \mathrm{k}}$ & $\sum_{j=1}^{k} q_{1 j}$ & $\overline{q_{1}}$ \\
\hline $\mathrm{X}_{2}$ & $\mathrm{q}_{21}$ & $\mathrm{q}_{22}$ & $\mathrm{q}_{23}$ & $\ldots$ & $\mathrm{q}_{2 \mathrm{k}}$ & $\sum_{j=1}^{k} q_{2 j}$ & $\overline{q_{2}}$ \\
\hline $\mathrm{X}_{3}$ & $\mathrm{q}_{31}$ & $\mathrm{q}_{32}$ & $\mathrm{q}_{33}$ & $\ldots$ & $\mathrm{q}_{3 \mathrm{k}}$ & $\sum_{j=1}^{k} q_{3 j}$ & $\overline{q_{3}}$ \\
\hline$\ldots$ & & & & & & & \\
\hline $\mathrm{X}_{\mathrm{n}}$ & $\mathrm{q}_{\mathrm{n} 1}$ & $\mathrm{q}_{\mathrm{n} 2}$ & $\mathrm{q}_{\mathrm{n} 3}$ & $\cdots$ & $\mathrm{q}_{\mathrm{nk}}$ & $\sum_{j=1}^{k} q_{n j}$ & $\overline{q_{n}}$ \\
\hline
\end{tabular}


The average rank is calculated by a formula

$$
\overline{q_{i}}=\frac{1}{k} \sum_{j=1}^{k} q_{i j} \quad(i=\overline{1, n}) .
$$

If there are coherent ranks, then reliability of examination can be expressed through concordat coefficient:

$$
W=\frac{S}{\frac{1}{12} \kappa^{2}\left(n^{3}-n\right)-k \sum_{j=1}^{k} T_{j}},
$$

where $S$ - the sum of squares of assessment deviations in results of each efficiency indicator expressed on the following formula:

$$
S=\sum_{i=1}^{n}\left[\sum_{j=1}^{k} q_{i j}-\frac{1}{n} \sum_{i=1}^{n} \sum_{j=1}^{k} q_{i j}\right]^{2}
$$

$\mathrm{T}_{\mathrm{j}}$ - an indicator of coherent ranks in estimates of $j$ of the expert

$$
T_{j}=\frac{1}{12} \sum_{l}^{L_{j}}\left(t_{l}^{3}-t_{l}\right)
$$

In a formula (2) $L_{j}$ - number of sheaves (types of the repeating elements) in estimates of $j$ of the expert $(j=\overline{1, n}), t_{l}$ quantity of the repeating elements in $l$ to a sheaf for the expert's $j$.

If the connected ranks are absent, then $T j=0(j=\overline{1, n})$ and coefficient of a concordat is calculated by a formula:

$$
W=\frac{S}{\frac{1}{12} \kappa^{2}\left(n^{3}-n\right)} .
$$

The concordat coefficient equals 1 if all rankings of experts are identical, and equals 0 if all of them are various. This coefficient represents a random variable [9]. For definition of assessing the importance of concordat coefficient we will calculate criterion of Pearson's coordination:

$$
\begin{aligned}
& \chi^{2}=\frac{S}{\frac{1}{12} k n(n+1)+\frac{1}{n-1} \sum_{j=1}^{k} T_{j}} . \\
& \text { If } \chi^{2}>\quad \chi^{2} \text { table where } \\
& \chi^{2} \text { table } \text { - the tabular value depending on }
\end{aligned}
$$
number of freedom degrees and the accepted significance value, a hypothesis of expert opinions coherence in ranking is accepted. Otherwise, when $\chi^{2}<\chi^{2}$ table, it is considered that expert opinions are not coordinated and significantly differ. The recommended significance value when checking a hypothesis of expert opinions coherence $0,05[10]$.

The SAW method (method of simple additive weighing) is applied to 
definition of assessing the ensuring food security in this work [11].

SAW method algorithm.

1. Let's consider $n$ of regions which will be estimated by $m$ criteria. Let's use

Table 3:Scale for determination of level of criterion of ensuring food security

\begin{tabular}{|c|c|}
\hline Importance & Definition \\
\hline 1 & The highest category of quality \\
\hline 3 & High category of quality \\
\hline 5 & Satisfactory category of quality \\
\hline 7 & Low category of quality \\
\hline 9 & Unprofitable category of quality \\
\hline $2,4,6,8$ & Intermediate values between the next values of a \\
& scale \\
\hline
\end{tabular}

According to the obtained data

we make a decision-making matrix

$$
B=\left(\begin{array}{cccc}
b_{11} & b_{12} & \ldots & b_{1 n} \\
b_{21} & b_{22} & \ldots & b_{2 n} \\
\ldots & \ldots & \ldots & \ldots \\
b_{m 1} & b_{m 2} & \ldots & b_{m n}
\end{array}\right),
$$

where $b_{\mathrm{ij}}$ - value of $i$ indicator for $j$ region $(i=\overline{1, m} ; j=\overline{1, n})$.

2. We find the best values of each indicator. If indicators of efficiency are minimized, then the best value of each indicator is calculated by a formula

$b_{i}^{*}=\min _{1 \leq j \leq n} b_{i j}, \quad(i=\overline{1, m})$;

if are maximized, then by a formula for this purpose a scale for determination of level for criterion of ensuring food security in regions (tab. 3). $b_{i}^{* *}=\max _{1 \leq j \leq n} b_{i j} \cdot \quad(i=\overline{1, m})$

3. We calculate the normalized matrix $\bar{B}$. Its elements are on formulas: $\bar{b}_{i j}=\frac{b_{i}^{*}}{b_{i j}}$, if indicators of efficiency are minimized;

$\bar{b}_{i j}=\frac{b_{i j}}{b_{i}^{* *}}$ if indicators of efficiency are maximized.

4. We calculate a matrix of the weighed efficiency indicators $\tilde{B}$. Elements of every line of the normalized matrix $\bar{B}$ are multiplied by 
corresponding sizes of the importance of efficiency indicators $g 1, g 2 \ldots, g m$.

5. Using a matrix of the weighed efficiency indicators $\tilde{B}$, the criterion of efficiency of each region is defined:

$$
K_{j}=\frac{1}{m} \sum_{i=1}^{n} \tilde{b}_{i j}, \quad(j=\overline{1, n}) .
$$

The optimal variant of the made decision and ranks (preference of alternatives) of possible decisions are established in value $\mathrm{K}_{\mathrm{j}}$. In case indicators of efficiency are minimized, then the rank " 1 " is appropriated to the region which has the greatest criterion of efficiency; a rank "2" - to the region which has the second-large criterion of efficiency; etc. A rank of "n" - to the region which has the smallest. If indicators of efficiency are maximized, then the rank "1" is appropriated to the region which has the smallest efficiency criterion, and a rank of " $\mathrm{n}$ " - to the region which has the greatest, i.e. in ascending order of efficiency criteria to the region.

\section{Results}

In this research the following criteria of ensuring food security were considered [1]:
1. daily energy value of a diet of the person $(\mathrm{X} 1)$;

2. providing diet of the person with main types of products (X2);

3. sufficiency of grain reserves in the state resources (X3);

4. economic availability of products (X4);

5. differentiation of food cost on social groups (X5);

6. capacity of domestic market for separate products (X6);

7. food independence on separate products (X7);

8. physical availability of foodstuff (X8);

9. $\quad$ stability of the food market (X9);

10. safety and quality of foodstuff (X10);

11. level of developing the agrarian sector (X11);

12. natural and resource potential and efficiency of its use (X12);

13. food independence of separate types of food (X13);

14. self-reliance level main types of food (X14);

15. volume of the state stocks of food (X15);

16. balance of foreign trade in food products (X16). 
For finding the numerical values of the importance of the considered criteria in ensuring food security we interviewed 17 experts. After processing the questionnaires in which it was offered to compare in pairs criteria of ensuring food security, determined a matrix of pair comparisons for objects (criteria of ensuring food security) with estimates by T. Saati's scale according to the scheme considered above and carried out mathematical calculations. Using a formula (1), the following numerical $g_{i}$ values are received $(i=\overline{1,16})$ :

Table 4:The normalized assessment of a priority vector $(g)$

\begin{tabular}{|c|r|}
\hline Criteria of ensuring food security & \multicolumn{1}{|c|}{ Normalized a vector } \\
\hline $\mathrm{X} 1$ & 0,050959 \\
\hline $\mathrm{X} 2$ & 0,079615 \\
\hline $\mathrm{X} 3$ & 0,055445 \\
\hline $\mathrm{X} 4$ & 0,088309 \\
\hline $\mathrm{X} 5$ & 0,090942 \\
\hline $\mathrm{X} 6$ & 0,053635 \\
\hline $\mathrm{X} 7$ & 0,041874 \\
\hline $\mathrm{X} 8$ & 0,074332 \\
\hline $\mathrm{X} 9$ & 0,055333 \\
\hline $\mathrm{X} 10$ & 0,09567 \\
\hline $\mathrm{X} 11$ & 0,024916 \\
\hline $\mathrm{X} 12$ & 0,03757 \\
\hline $\mathrm{X} 13$ & 0,055207 \\
\hline $\mathrm{X} 14$ & 0,051049 \\
\hline $\mathrm{X} 15$ & 0,060234 \\
\hline $\mathrm{X} 16$ & 0,084907 \\
\hline$\sum$ & 1 \\
\hline
\end{tabular}


Numerical values of the criteria

values of ensuring food security gi

$(i=\overline{1,16})$ are presented in Figure.

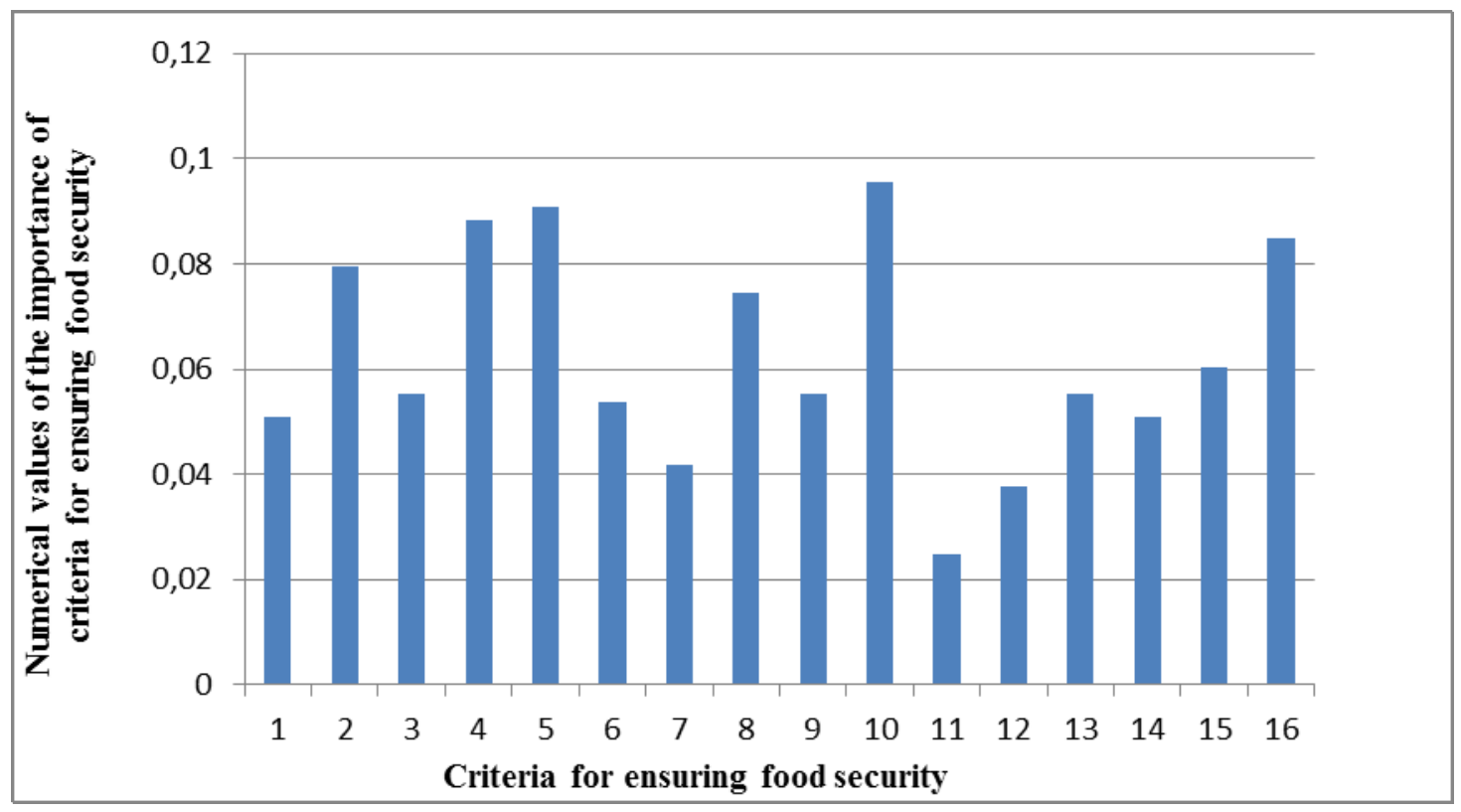

Fig. 1. Numerical values of the importance for ensuring food security criteria

When checking coherence of opinions of the 17 experts the concordat coefficient (3) for finding the numerical values of the criteria values of ensuring food security made 0,8658 that means rather high coherence of this expert group.

Calculated according to (4) value $\chi^{2}=202,692$ there is more tabular value at significance value $\alpha=0,05$ and to number of freedom degrees $v=\mathrm{n}-1=15 \chi^{2}$ табл $=25$. The hypothesis of expert opinions coherence means is accepted.

On the basis of the SAW method we calculated criteria of optimality and defined ranks for regions of Volga Federal District. This method allows estimating the level of ensuring food security of these regions.

As a result of poll of the same 17 experts mentioned above for assessing the level of ensuring food 
security criterion the decision-making matrix was drawn. In this case when checking coherence of opinions of 17 experts the concordat coefficient made 0,9171 that means rather high coherence of this expert group.

Calculated according to (4) value $\chi^{2}=202,6791$ there is more tabular value at significance value $\alpha=0,05$ and to number of degrees of freedom $v=\mathrm{n}-1=14-1=13$ $\chi_{\text {табл }}^{2}=22,4$

The hypothesis of expert opinions coherence means proved itself.

Using numerical values of the priority importance of the criteria for ensuring food security found by means of a pair comparison methods with use of a scale of Saati (tab. 4) the efficiency criteria were calculated and ranks of each region (tab. 5) are defined.

Table 5:Level assessment of criterion for ensuring food security in the regions of Volga Federal District

\begin{tabular}{|c|c|c|c|c|c|c|c|c|c|c|c|c|c|c|}
\hline & 1 & 2 & 3 & 4 & 5 & 6 & 7 & 8 & 9 & 10 & 11 & 12 & 13 & 14 \\
\hline & 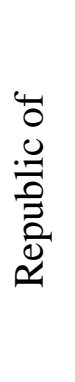 & 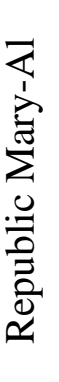 & 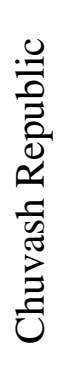 & 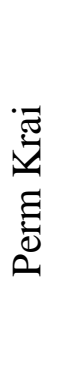 & 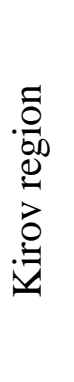 & 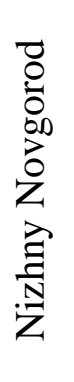 & 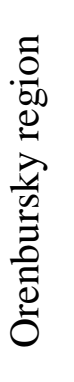 & 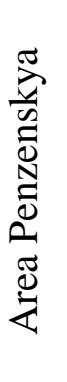 & 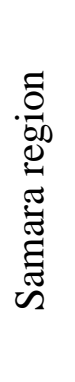 & 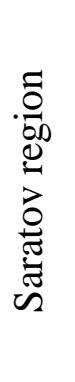 & 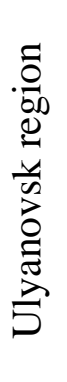 & 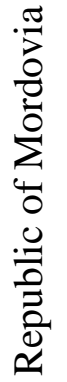 & 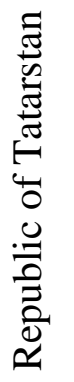 & 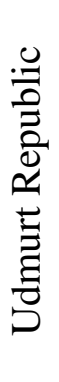 \\
\hline K & $\begin{array}{l}\tilde{n} \\
\tilde{n} \\
0 \\
0\end{array}$ & $\begin{array}{l}\infty \\
\infty \\
0 \\
0 \\
0\end{array}$ & $\begin{array}{l}\tilde{n} \\
\stackrel{n}{0} \\
0 \\
0\end{array}$ & 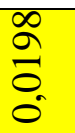 & $\begin{array}{l}\overline{0} \\
0 \\
0 \\
0\end{array}$ & 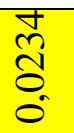 & 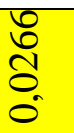 & 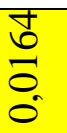 & $\begin{array}{l}\widehat{\widehat{\Omega}} \\
\text { ठิ }\end{array}$ & 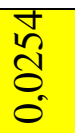 & $\begin{array}{l}\tilde{m} \\
0 \\
0 \\
0\end{array}$ & $\begin{array}{l}\vec{J} \\
\dot{\sigma} \\
0\end{array}$ & $\begin{array}{l}0 \\
\frac{0}{2} \\
0 \\
0\end{array}$ & 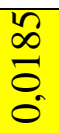 \\
\hline $\begin{array}{l}\text { Ran } \\
\mathrm{k}\end{array}$ & 1 & 8 & 12 & 7 & 14 & 6 & 4 & 10 & 3 & 5 & 13 & 11 & 2 & 9 \\
\hline
\end{tabular}

So, assessing the level of criteria for ensuring food security in the regions of Volga Federal District is presented in the Figure. 


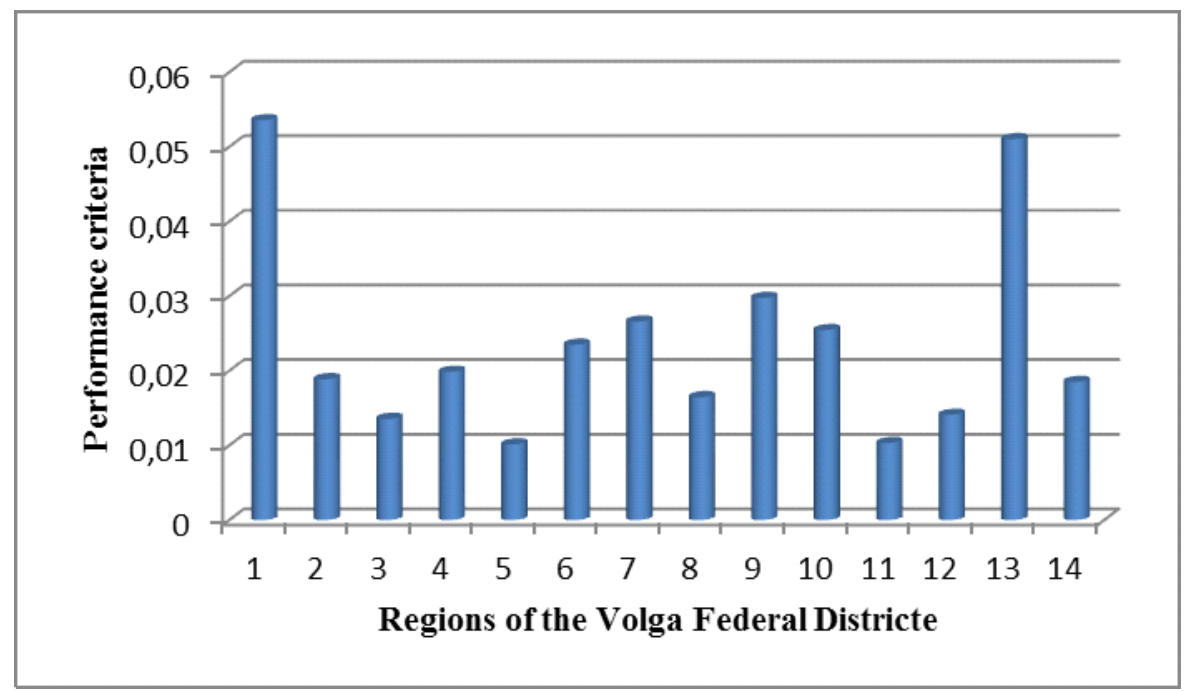

Fig. 2. Level of ensuring food security in the regions of Volga Federal District

The submitted chart out the analysis of assessing the level of demonstrates levels of ensuring food ensuring food security in the largest security in the regions of Volga Federal regions of the Republic of Tatarstan. District. Level assessment of ensuring food

By means of the economicsecurity in the largest regions of the mathematical model constructed on the Republic of Tatarstan is presented in basis of the SAW method we also carried table 6 .

Table 6:Assessing the level of criterion for ensuring food security the largest regions of $R T$

\begin{tabular}{|c|c|c|c|c|c|c|c|}
\hline & 1 & 2 & 3 & 4 & 5 & 6 & 7 \\
\hline & 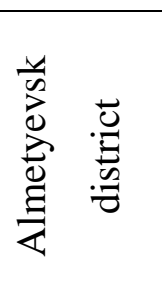 & 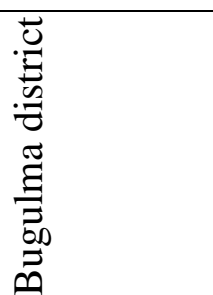 & 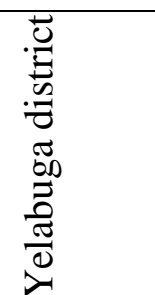 & 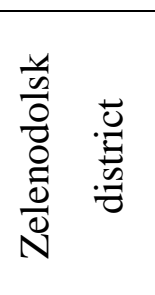 & 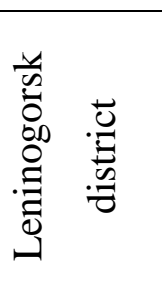 & 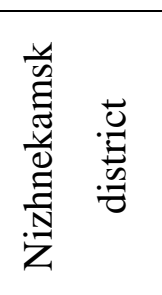 & 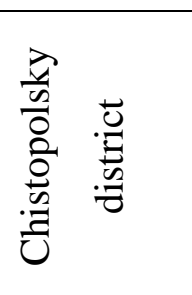 \\
\hline K & 0,04603 & 0,04183 & 0,04487 & 0,04220 & 0,04178 & 0,04627 & 0,04377 \\
\hline Rank & 2 & 6 & 3 & 5 & 7 & 1 & 4 \\
\hline
\end{tabular}


Assessing the level of criterion

for ensuring food security of the largest

regions of RT is given in the Figure.

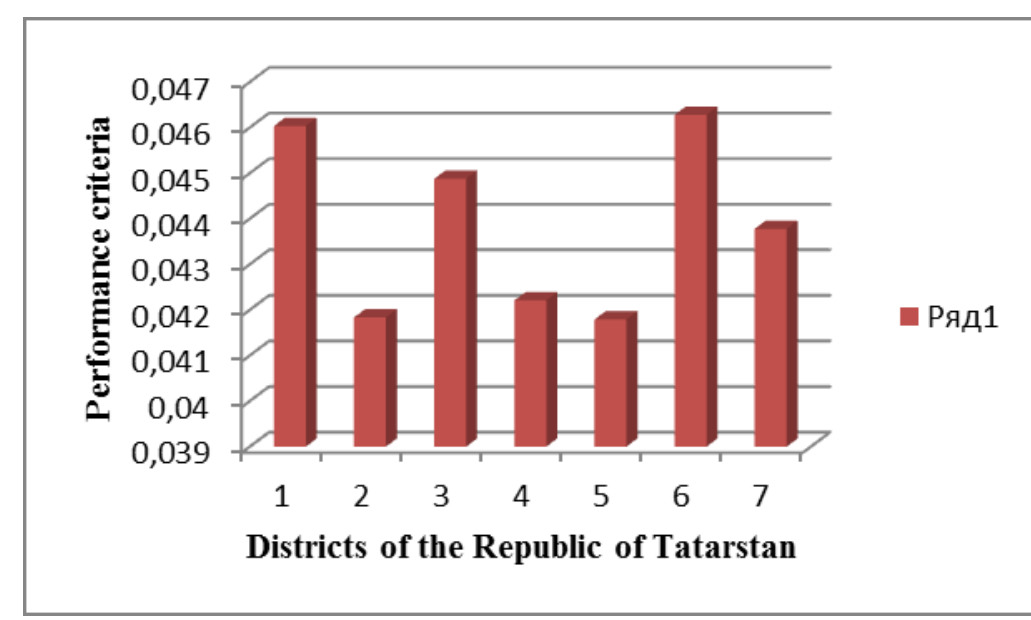

(row)

Fig. 3. Assessing the level of criterion for ensuring food security of the largest regions of $R T$

In this case we interviewed 15 experts. Professors and associate professors of the Kazan higher educational institutions acted as experts. When checking coherence of opinions of these experts the concordat coefficient made 0,8891 that means rather high coherence of this expert group.

Calculated according to (4) value $\chi^{2}=80,019$ there is more tabular value at significance value $\alpha=0,05$ and to number of freedom degrees $v=\mathrm{n}-1=7-1=6 \chi^{2}$ табл $=12,6$. The hypothesis of expert opinions coherence means is accepted.

\section{Discussion}

The results on Volga Federal District presented in fig. 2 demonstrate that the level of ensuring food security in the Republic of Bashkortostan and the Republic of Tatarstan is at $\mathrm{s}$ rather high level. The lowest levels of ensuring food 
security are in the Kirov and Ulyanovsk regions.

The results received by us on RT demonstrate that the level of food security has the highest assessment in the following regions of RT: Almetyevsk, Nizhnekamsk. This results from the fact that these areas are in big dependence on the petrochemical, oil processing and power generating industry of Tatarstan from which they receive the majority of the budgetary receipts.

\section{Conclusions}

Component organization of ensuring food security is important in assessing the ensuring food security of the region.

The model of assessing the ensuring food security offered above allows to define in management process of regional economic system regions with the low level of food security and to take measures in improvement of this question. It increases effective process management of ensuring food security. Such approach in estimation of ensuring food security in regions allows to reveal shortcomings and to eliminate them.

On the basis of elements of the economic-mathematical modeling the method of estimating ensuring food security on the example of the Volga Federal District and the Republic of Tatarstan which helps to reveal regions with the low level of food security and by that to take measures for improvement of a situation in these regions is developed.

\section{Summary}

Thus, application of methods of economic-mathematical modeling allowed to present objective assessing the level of sustainable development by the food sphere of economic security on the example of the regions of Volga Federal District and municipalities which are a part of the Republic of Tatarstan that allowed proving the maintenance of measures for the operating influence.

\section{Acknowledgements.}

This work was performed in accordance with the Russian Government Program of Competitive Growth of Kazan Federal University

\section{References}

Doctrine of food security of the Russian Federation. [Electronic resource]: 
ISSN | 2179-7137 | http://periodicos.ufpb.br/ojs2/index.php/ged/index

Decree of the Russian President of 30.01 .2010

No.

120.

URL:http://www.kremlin.ru/news/6752

Antamoshkina E. N. Economic indicators of food security in the south of Russia//Economy and management of innovative technologies. 2014. No. 3 [An electronic resource]. URL: http://ekonomika.snauka.ru/2014/03/38 $\underline{52}$

Naydanova E. B, Tushkayev L. V. Economic indicators of food security in Siberian Federal District//Basic researches. - 2015. - No. 6 (part 3) - Page 597-601

Saaty T. A Scaling Method for Priorities in Hierarchical Structures, Journal of Mathematical Psychology, Vol. 15, No. 3, 1977, pr. 234-281.

Zavadskas E., Kaklauskas A. A new method of complex evaluation of projects based on multiple criteria analysis and the principle of proportionality. In: Integrating Technology \& Human Decisions: Global Bridges into the 21st Century, vol. II: Proceedings of 5th International
Conference,

Athens,

Greece/D.K.Despotis, C.Zopounidis (Eds.). 1999, pp. 2051-2053.

Larichev O., Kochin D., Kortnev A. Decision Support System for Classification of a Finite Set of Multicriteria Alternatives, Journal of Decision Support Systems, 33, 2002, pp. 13-21.

Larichev O., Kochin D., Ustinovichius L. Multicriteria Method of Choosing the Best Alternative for Investments, International Journal of Strategic Property Management, Vol. 7, No. 1, 2003, pp. 33-43

Evlanov L. G. Theory and practice of decision-making. - Moscow: Economy, 1984. - 176 pages.

Kendall M. Rank Correlation Methods. London: Griffin, 1970

Evlanov L. G., Kutuzov V. A. Expert estimates in adoption of planned decisions. - M.: Economy, 1978 - 113 pages. 
Periódico do Núcleo de Estudos e Pesquisas sobre Gênero e Direito Centro de Ciências Jurídicas - Universidade Federal da Paraíba V. 8 - No 05 - Ano 2019 ISSN | 2179-7137 | http://periodicos.ufpb.br/ojs2/index.php/ged/index

Hwang C. L., Yoon K. Multiple

Attribute Decision Making Methods and Applications. A State of the Art Survey.

New York: Springer Verlag, Berlin,

Heidelberg, 1981 